Article

\title{
Sustainability in Higher Education: The Relationship between Work-Life Balance and XR E-Learning Facilities
}

\author{
Rocsana Bucea-Manea-Țoniş ${ }^{1}$ (D), Radu Bucea-Manea-Țoniş ${ }^{2}$, Violeta Elena Simion ${ }^{1}$ (D), \\ Dragan Ilic $^{3,4}$, Cezar Braicu ${ }^{2,5}$ and Natalia Manea ${ }^{6, * \text { (D) }}$ \\ 1 Central Research Institute, 030167 Bucharest, Romania; rocsense39@yahoo.com (R.B.-M.-T,.); \\ simion.violeta.elena@gmail.com (V.E.S.) \\ 2 Faculty of Economic Sciences, Hyperion University, 030615 Bucharest, Romania; \\ radub_m@yahoo.com (R.B.-M.-T.); cezar_braicu@hotmail.com (C.B.) \\ 3 Faculty of Economics and Engineering Management, University Business Academy, 21000 Novi Sad, Serbia; \\ prof.dragan.ilic@gmail.com \\ 4 International Department, Budapest Metropolitan University, 1148 Budapest, Hungary \\ 5 Academy of Economic Sciences, 010731 Bucharest, Romania \\ 6 Department of Economic Engineering, Faculty of Entrepreneurship, Business Engineering and Management, \\ University POLITEHNICA of Bucharest, 060042 Bucharest, Romania \\ * Correspondence: natalia.manea@upb.ro; Tel.: +40-723-087-095
}

Received: 2 June 2020; Accepted: 17 July 2020; Published: 21 July 2020

check for updates

\begin{abstract}
Nowadays, collaborative learning is proving to offer solutions to new inclusivity research challenges, and most importantly, can help ensure sustainable education. Collaborative learning can strengthen positive attitudes towards learning, improve performance in academic results, and enhance self-esteem, by promoting interaction and mutual support among young people. Extended reality (XR), associated with collaborative learning, offers a further advantage by facilitating deep comprehensive learning. An online survey was conducted to investigate respondents' views on the impact and influence of virtual technologies on work, study, and social life. Respondents $(n=1032)$ were recruited from Serbia, Romania, and Hungary, from five public and private universities. The study reveals students' perceptions of e-learning and XR immersion. The data were analyzed by using a combination of descriptive techniques from PSPP (GNU open source SPSS-Statistical Package for the Social Sciences, Free Software Foundation, Boston, MA, USA), and by designing a regression model to evaluate the work-life balance. This regression model shows that the work-life balance is positively influenced by the inclusion of XR facilities in the e-learning process, along with an increased level of culture and living standard. The higher living standard of a student is associated with higher digital competence and more financial resources available to invest in technology.
\end{abstract}

Keywords: e-learning; sustainable education; Virtual Reality (VR); Augmented Reality (AR); Extended Reality (XR); work-life balance

\section{Introduction}

We live in a society that is increasingly concerned about issues related to the sustainability of its own models-educational, economic, and social. In the era of the Internet of Things (IoT), Augmented Reality (AR), Virtual Reality (VR), and collaborative learning offer a complete experience during a student's process of acquiring information, and enable the spread of creativity. VR and AR allow students to perform experiments in a safe environment [1-3]. Smart education uses new technology that blurs the line between what is real and what is computer-generated, offering a complete experience 
by enhancing the senses-vision, hearing, smell, and touch [4,5]. VR and AR immersion in education also has a positive impact on the IoT smart environment. VR and AR are followed by Mixed Reality (MR), which is an AR+ that places objects or creatures just like the AR only with their ability to engage in the real, physical world around them and vice versa. The integration of collaborative e-learning, AR, VR, and MR evolves into Extended Reality (XR), allowing the user to bend reality [6-9]. Most likely, these will also evolve into Mobile AR and Location-Based VR. Education for Sustainable Development, or Education for Sustainability (EfS), is a process that develops people's awareness, competence, attitudes, and values, enabling them to be effectively become involved in sustainable development at the local, national, and international levels, and helping them to work towards a more equitable and sustainable future. In particular, it enables people to integrate social and cultural considerations with environmental and economic decision-making [10].

As a principle, sustainable development needs to be applied in all areas in order to meet basic material needs, provide optimization of resources, and ensure quality of life in terms of health and education. In this context, we decided to examine students' opinions regarding the importance of XR in e-learning. The students came from Serbia, Romania, and Hungary, from five different universities. We selected these countries as some of the local teachers are reluctant to apply new technologies as part of the educational process. Understanding students' needs will enable teachers to adapt and become more accustomed to the new technologies.

\section{Background of Literature}

Universities need to allocate resources intelligently to become sustainable and to provide students with life experiences in a sustainable environment. They must be a catalyst for necessary changes in society so that their graduates can be part of the transformation of the whole society, in the direction of sustainable development. In addition, there is an expectation from society that universities will play an important role in facilitating education that allows current and future generations to redesign their activities, as well as their personal and professional life, to create a sustainable future. Education can only be sustainable through a concerted approach. Collaborative learning includes student-to-student collaboration, teacher-to-student collaboration, student-to-teacher collaboration, and student-to-machine interaction. If collaborative learning is associated with the halo effect, students can be projected in time to when the event happened and be immersed in "another time and place" that is easy to understand. Collaborative learning brings about innovation in teaching and learning methods, facilitating the presentation of learning content among students and teachers [11,12] through interconnected mobile devices. Wireless connection increases students' engagement in accessing information and fosters collaboration among them [13]. The biggest positive impact on students derived from the collaborative environment was through AR learning applications [14] and game-based learning [15].

VR and AR associated with collaborative learning bring about two other advantages: deep comprehensive learning facilitated by the "learning-by-doing effect," as well as the engagement of all the senses at the same time during simulated reality $[16,17]$.

The literature review reveals some important benefits of the e-learning environment in the era of IoT $[18,19]$. It brings about spatial delocalization and experimentation in different subject matter areas; it promotes innovations, such as informal and ludic activities; it encourages experimentation with virtual environments; it increases the motivation for learning; it involves the joy of being part of specific social networks and creativity; and it leads to the inception of new scales of value.

The characteristics of $X \mathrm{R}$ are: presence/teleportation, which refers to how immersive the experience is, i.e., how real it feels; haptics, the association with tactile experiences while immersing in XR (driving a car, playing a sport, designing a house, painting, performing surgery, combining chemical substances, doing physics experiments, etc.); interactiveness, which refers to multiple ways of joining in the simulation/adventure, facilitated by different types of media content within an XR application; imagination and $5 \mathrm{D} X \mathrm{R}$, whereby the experience becomes more immersive if the content is presented in fourth and fifth 
dimensions; a stereoscopic effect, obtained when two videos or photos are taken from slightly different angles and then viewed together giving the appearance of depth; field of view-for a real experience, the application has to allow a 360-degree view (moving the eyes, head, or body will change the entire perspective and experience, as in real life); the lag between an XR stimulus and the response, which has to be as short as possible for an intense experience; and simulator sickness, a side effect that rarely occurs due to the disconnect between what is seen and what is felt generating confusion (the clues of visual and physical movement are not registered at the same time). The XR experience affects all the senses: visual (using hamlets, neurotransmitters, goggles: head-mounted displays (HMD), Oculus Rift), auditory (e.g., audio tools such as Oculus or KAI Tech), tactile (using haptic devices to send vibrations/electrostatic shock: gloves, backpacks, etc.), olfactory (devices that change the smell in the VR environment), and taste (which works more as an autosuggestion facilitated by the visual and auditory senses). These applications use bodysuits and vibration controllers for the kinetic stimulation of the entire body. All these elements have to be considered as part of the new teaching methodologies.

The study records the perceptions that students from three Eastern European countries have of $\mathrm{XR}$ in the e-learning process. In these universities, $\mathrm{XR}$ technologies have not been adopted yet. Teachers observed the enthusiasm of millennial students for using new technologies as part of the learning process. Students are very active, always on the move, and ready to test and to learn by doing. This means that the learning content should be adapted to:

- Where they are: if they are at the office, on campus, traveling, etc.; if they have spare time, students should be able to access the learning content remotely as a podcast, YouTube video, or XR application;

- When they can access the information (a very flexible schedule, $24 \mathrm{~h}$ a day);

- How they can assimilate it (written text is very valuable, but it can be more easily understood if it is associated with photos, videos, simulations, applications, etc.).

Multisensory learning is preferred by millennials due to different IQ levels, which varies between individuals. This method presents the learning content through different sources and senses (sight, touch, hearing, and smell) for effective learning [20]. The potential of this technology is increased through its incorporation in different disciplines: medicine, history, psychology, economics, architecture, etc. With AR in education, learners can understand concepts better, thanks to the use of 3D models. AR allows for adding a new layer of information to physical reality using a smartphone or tablet. Using this technology, teachers can provide interesting presentations that will attract students' attention, even in the case of a difficult topic [21].

Although research on the usefulness of these technologies in education has been part of many studies [22-25], their integration into the educational process is still difficult for some developing societies. However, improving students' motivation, satisfaction, and performance can increase their contribution to the university environment [6].

It is also important to have a very interactive form of evaluation (such as Kahoot games or Google forms with integrated video). They are used after the content learning, to cement the information. VR/AR is already applied to training and development by various industries and U.S. universities [17].

Based on the theory of self-determination, Mahmud et al. (2020) encourage student participation and learning by introducing game elements into the learning process, in which the teacher plays a role as an agent in this online gamification learning context [26]. Providing teacher feedback and recognition, and communicating with students, encourages their participation in activities. This suggests that the presence of a teacher encourages student involvement in online gamified activity, consistent with many studies that have found a correlation between teacher presence and student performance in online learning [27].

The current approach to AR and VR in the educational field is found in the context of online and ubiquitous training, and mobile technology in education in order to gain sustainability. In the educational context of the countries studied, a number of barriers to incorporating sustainable 
development into the curriculum must be overcome. Thus, it would be useful to rigorously analyze the existing curricula or redefine them, following the reconsideration of the competencies necessary for each university qualification so that new disciplines are introduced, in the context of sustainable development. Significant investment in staff development can strengthen the capacity to adapt to the new technologies and help teachers develop new motivational strategies [28].

\section{Conceptual Framework for Sustainable Development through the Inclusion of XR in the Education Process}

In a time of crisis (such as that caused by COVID-19), distance learning and MOOCs (Massive Open Online Courses) are adequate tools for sustainable higher education (HE). Thus, some of the HE priorities are [29]:

- Tackling teachers' and students' skill gaps and mismatches.

- Increasing the attractiveness of and reforming curricula for STEM (Science, Technology, Engineering and Mathematics) with a STEAM (Science, Technology, Engineering, the Arts and Mathematics) approach including real-world applications, inquiry-based and ICT-enriched learning, and collaborative practices, including university-business cooperation.

We started from the evidence that teachers have a huge responsibility to equip students with ICT literacy that meets the requirements of the 21st century. At the same time, teachers are no longer the only source of knowledge for students; they have a more complex role, to deliver information, to coordinate the learning process and, last but not least, to facilitate access to learning and technology. The study looks at the extent to which students from Eastern European universities are prepared for the inclusion of XR technology in their learning and their personal lives, so that teachers can become more creative and flexible in learning. We aim to assess whether the reluctance to approach these technologies is cultural or otherwise, and whether they are desired by students [30-33].

To this end, we designed a survey that emphasizes the tools/technologies able to increase the attractiveness of digital courses and, at the same time, help teachers to gain horizontal competencies. These technologies will improve, rewarding excellence in learning, teaching, and skills development; they will also facilitate the training of academics in new and innovative pedagogies, including transdisciplinary approaches, new curriculum design, and delivery and assessment methods linking education with research and innovation to foster innovative practices in digital education.

Nowadays, university-business interactions involve a skills mismatch. As stated in the "Agenda for the Modernization of Europe's Higher Education Systems", globalization and digitalization emerged as important "megatrends" directly affecting higher education institutions and the world for which they are preparing graduates. For that reason, curricula should be updated with new educational modules, exploring the intersection of regulation, science, technology, and law to meet the needs of the rapidly changing scientific and policy landscape. At the same time, employment insecurity is likely to increase with the advent of the 4th Industrial Revolution. At the top of the European agenda is the enhancement of skills for better employability by improving the quality of education, including the active use of cyberspace for educational purposes by students, faculty, and teaching staff [30-33].

According to the "A New Skills Agenda for Europe", by 2025, almost half of all job openings in the EU will require higher qualifications (usually awarded through academic and professional programs at a tertiary level). Skills developed through these programs are generally considered to be drivers of productivity and innovation [30-33].

\section{Research Hypothesis and Proposed Model}

The literature review shows that the adoption of $\mathrm{XR}$ in teaching has two major requirements: the technology must fit into instructors' existing practices, and the cost cannot be significantly higher than that of the alternatives already in use. It is very important for students to be able to buy the technology. Additionally, the integration of XR into the curriculum faces two major challenges: time 
and skills [34]. There is a strong correlation between cultural/living standards and the decision to invest in technology. The application of VR technology to Internet education has injected fresh blood and enhanced its competitiveness in the education field [35].

A study of professors using XR in their teaching and research identified learning goals that are effectively supported by XR technology, as well as methods for integrating XR into pedagogy. Educational background has a potential effect on each dimension of digital social and political life [36]. Different levels of education and digital literacy have a positive correlation with digital social life. Digital opportunities and information capabilities are highly positively correlated to educational background and citizen participation [37].

A balance between work, learning, and personal life, will facilitate behaviors that are associated with safety and well-being [38]. The literature review shows that flexible working context and schedules will be associated with healthy employees, while a lack of control over working time creates risk groups prone to disruptions to well-being [39,40]. XR will make teaching and learning more interactive, facilitate deep learning, and make it fun to acquire knowledge. Thus, introducing XR facilities into the e-learning process is an important step that will contribute to a good work-life balance. However, there is still a lot of work to be done [41,42].

The main aim of this article is to address the issue of adaptation through changes of mindset on the use of new technologies. We start by evaluating the current e-learning perceptions of students from five universities in three different countries (Romania, Hungary, and Serbia). The objective of this research was to identify students' opinions regarding the inclusion of $X R$ in the learning process. We also analyzed the impact of XR technologies on the work-life balance. The research hypothesis of the study (H1) is that the balance between working and social life is influenced by the inclusion of XR facilities in the e-learning process. If students have a high level of culture and living standards, this will allow them to invest in technology. A higher level of culture is also associated with higher digital competence as well as being keen on new technologies.

The second objective of the study is to demonstrate how important it is for small countries such as Romania, Hungary, and Serbia to adapt their curricula and positively influence teachers' attitudes towards XR technologies. In these countries, teachers are reluctant to adopt new methods of teaching, which includes XR technologies. A good example of combating this tendency is the University of Graz, which created the Social Internet of Things, combining the advantages of social media and new technologies. The literature emphasizes the need for adaptability in higher education, including the flexibility of teachers regarding working from home and the work-life balance, which will have a great impact on the social-economic system $[3,41,43]$ by:

- Encouraging universities to be adaptable to current challenges

- Reducing costs for transportation and health expenses

- Transfrontier collaboration in real time

- Higher creativity, innovation, and productivity of the employees

- Healthier, happier, and more responsible employees

- Higher sustainable corporate responsibilities following the principles of the circular economy.

Thus, the aim is to support universities in achieving their main goals: adopting new approaches, adding new programs, changing the curricula, including data literacy, designing new courses, using the most advanced technologies, and creating new learning environments dedicated to research and education to prepare students and staff to face current and future challenges. The physical learning environment has to be improved via environments for problem-based learning, and learning-by-doing activities for interdisciplinary teams that use blended learning. Students from different fields such as computer science and the social sciences can be brought into the same team to solve problems due to the cross-fertilization of knowledge (an example of how digital skills promote entrepreneurial and management skills). These specialists will shape the digitally transformed society, which is already present (cybermarketing is more efficient and more convenient than classic publicity in newspapers and 
$\mathrm{TV}$, online transactions, distance learning, e-commerce, etc.). For students with digital competencies, it will be fun to use these in their future work and thus, the economy will benefit from it, more so under the green and circular economy principles [30-32].

Universities have to rethink strategic management regarding digital competencies and their implementation into the education process. Thus, universities must ensure that graduates have the skills to make use of new technologies. Universities should prepare students for labor markets where the probability of disruption is high, and companies have to anticipate their future employees' capacities and abilities $[35,43,44]$.

Knowledge and technological transfer will have a major, positive impact on the business field. Companies have to be able to auto-evaluate, discover weaknesses regarding disruptive technologies, and face continuous economic challenges. Thus, companies will become more productive and innovative. They will have more motivated, skilled, innovative, healthy, and well-adapted employees. Respecting the Erasmus+ principles, and correlating the indicators with these principles, the old companies will be more sustainable, and new spin-offs will restart the economy in these difficult times [30-32].

\section{Research Methodology}

\subsection{International Survey}

An online survey was conducted to investigate respondents' view on how much work, study, and social life are influenced by virtual technologies. Respondents $(n=1032)$ were recruited from three countries (Serbia, Romania, and Hungary) and five public and private universities: Business Academy University Novi Sad $(n=10 \%)$, University of Novi Sad $(n=13 \%)$, Spiru Haret University Bucharest $(n=35 \%)$, Academy of Economic Studies Bucharest $(n=30 \%)$, and Budapest Metropolitan University $(n=11 \%)$. These universities have strong collaborations and intend to implement a project to introduce VR/AR technologies into the e-learning process.

The specific steps used in the sociological research were as follows: the establishment of research assumptions for verification, the setting of objectives, and the study of various theoretical orientations, which resulted in several concepts. To determine the materials to be used, the sampling of the investigated theme was followed by the choice of the collection method and, finally, the analyses of the data were: establishing the assumptions of the research to check them, establish the objectives, followed by the study of the various theoretical orientations resulting in a series of concepts. We did a sociological survey using a questionnaire consisting of a series of semi-closed and dichotomic/closed questions. The questionnaire also included open-ended questions to enable subjects to inform us about novelties/trends in the field or suggest new solutions. The survey was administered via LimeSurvey and comprised two sections. The first section asked for information about gender, age, ethnicity, and the perspective on learning with e-learning platforms (Table 1).

The next section evaluates to what extent virtual technologies can influence learning facilities. Respondents answered a series of questions to indicate in which areas of study they think XR can be used, and the advantages and disadvantages of the inclusion of XR into e-learning platforms, mobile devices, and social media apps used for e-learning. Then, a regression model has been designed to show to what extent a balance can be achieved between social life and work, through the use of virtual technologies in e-learning. 
Table 1. Respondents' demographic information and point of view about e-learning platforms.

\begin{tabular}{|c|c|c|c|}
\hline & $\begin{array}{c}\text { Total Sample } \\
n=1032\end{array}$ & $\begin{array}{l}\text { E-Learning Platform Users } \\
\qquad N=1008\end{array}$ & $\begin{array}{l}\text { E-Learning Platform Nonusers } \\
\qquad N=24\end{array}$ \\
\hline \multicolumn{4}{|c|}{ Gender } \\
\hline Female & 609 & 589 & 20 \\
\hline Male & 423 & 419 & 4 \\
\hline \multicolumn{4}{|c|}{ Age (years) } \\
\hline $18-24$ & 372 & 372 & 0 \\
\hline $25-34$ & 423 & 423 & 0 \\
\hline $35-44$ & 196 & 187 & 9 \\
\hline $45-54$ & 31 & 19 & 12 \\
\hline$>55$ & 10 & 7 & 3 \\
\hline \multicolumn{4}{|c|}{ Ethnicity } \\
\hline Serbian & 237 & 230 & 7 \\
\hline Romanian & 671 & 659 & 12 \\
\hline Hungarian & 124 & 119 & 5 \\
\hline \multicolumn{4}{|c|}{ E-learning platforms involve: } \\
\hline In-depth technical knowledge & 135 & 122 & 13 \\
\hline In-depth knowledge in the field of study & 258 & 258 & 0 \\
\hline The habit of learning alone and organizing time and study materials & 516 & 516 & 0 \\
\hline They do not require any prior technical knowledge & 123 & 112 & 11 \\
\hline \multicolumn{4}{|c|}{ E-learning platforms have as their main advantages: } \\
\hline Allow materials to be studied electronically & 165 & 151 & 14 \\
\hline Enable online conferencing via Skype & 83 & 83 & 0 \\
\hline Allow virtual classes for teamwork on different projects & 124 & 124 & 0 \\
\hline Allow synchronous and asynchronous messaging & 83 & 83 & 0 \\
\hline Allow continuous assessment of knowledge & 103 & 103 & 0 \\
\hline
\end{tabular}


Table 1. Cont.

\begin{tabular}{|c|c|c|c|}
\hline & $\begin{array}{c}\text { Total Sample } \\
n=1032\end{array}$ & $\begin{array}{l}\text { E-Learning Platform Users } \\
\qquad N=1008\end{array}$ & $\begin{array}{l}\text { E-Learning Platform Nonusers } \\
\qquad N=24\end{array}$ \\
\hline Reduce transportation costs (not traveling to college) & 134 & 134 & 0 \\
\hline Provide more time to study & 144 & 144 & 0 \\
\hline Provide more efficient technical solutions to the learning process & 114 & 114 & 0 \\
\hline Objective evaluation & 72 & 72 & 0 \\
\hline I do not consider it an effective solution for learning & 10 & 0 & 10 \\
\hline \multicolumn{4}{|c|}{ The e-learning system allows a balance to be struck between learning and social life } \\
\hline Yes & 764 & 764 & 0 \\
\hline No & 83 & 73 & 10 \\
\hline I don't know & 185 & 180 & 5 \\
\hline \multicolumn{4}{|c|}{ A lack of e-learning platforms would translate into a lower level of culture and living standards (economic) } \\
\hline Yes & 712 & 712 & 0 \\
\hline No & 113 & 23 & 90 \\
\hline I don't know & 207 & 90 & 117 \\
\hline
\end{tabular}




\subsection{Construction and Validation of the Questionnaire}

The tool used to collect the data was a questionnaire that was adapted to the characteristics of the respondents. The questionnaire was built on the principle of the respondent's effort. This principle requires that questions that need greater mental effort to answer be placed at the heart of the questionnaire. The questionnaire consisted of closed, open, dichotomous, trichotomous, and multihotomic questions, and covered all existing possibilities.

Before the pretest, the questions of the questionnaire were evaluated according to the ease of understanding. Each question was checked and validated so that it was:

- $\quad$ appropriate to the purpose of the research and indispensable;

- clear and intelligible;

- interpreted in the same way by each respondent;

- not likely to generate deliberately inaccurate answers.

The questionnaire included the questions selected after evaluation and validation. The questionnaire was tested by a pilot study that aimed to identify and eliminate ambiguities. The validation consisted of sending the online questionnaire to a small number of respondents $(n=25)$ from all university centers participating in the study. The information gathered from this pilot study led to the improvement of the structure of the initial questionnaire (the deletion, addition, or reformulation of some questions). The questionnaire included 11 questions.

\subsection{Data Analysis}

Data were analyzed using a combination of descriptive techniques using PSPP, including segmentation of respondents by demographic (gender, age, ethnicity) and point of view about e-learning platforms and $\mathrm{XR}$ technologies, as well as developing a regression model for evaluating the balance between work and social life.

Respondents in this study were predominantly female (59\%). Of these, 3.4\% were nonusers of e-learning platforms, while for male respondents, out of the $41 \%$, only $0.9 \%$ were nonusers of e-learning platforms (Table 1). The sample, thus, had more males who were familiar with e-learning platforms. By contrast, $3.4 \%$ of females stated that they were reluctant to use e-learning platforms for education. A series of studies on the use of new media equipment by gender [45] showed that women, although more open to new ideas and online applications, are perceived as having lower skills in the virtual environment $[45,46]$. Their reaction to this risk makes them more appreciative of the virtual environment control $[47,48]$.

Most of the respondents (77\%) were young people: $41 \%$ were aged between 25 and 34 years old and $36 \%$ were aged between 18 and 24 years old, while $19 \%$ were $35-44$ years old and $4 \%$ were older than that (Table 1). The younger groups were familiar with e-learning platforms and considered them appropriate for education, in contrast with people over 45: 39\% of them were nonusers of e-learning platforms. Previous studies on the influence of e-learning on adults showed the direct and positive influence of the family, as emotional support, for adults. It has also been observed that the similarities between women and older adults are due not specifically to gender, but to social context [49].

Regarding ethnicity, $65 \%$ were Romanian, $23 \%$ were Serbian, and $12 \%$ were Hungarian. More than $95 \%$ of each ethnic group were familiarized with e-learning platforms. This is a result of the area from which the project was coordinated (Table 1)—respondents were chosen from universities.

\section{Results and Discussion}

\subsection{Respondents' Demographics and Their Opinions about E-Learning Platforms}

Most of the students (516 respondents) said that the most important benefit of e-learning platforms is the ability to learn alone and organize the time and material that has to be comprehended. Sometimes it is difficult to understand new and complex concepts; 258 of the respondents using the e-learning 
platform said so. This is why some students (122 e-learning platform users versus only 13 nonusers) consider that in-depth knowledge in the field of study is required in the e-learning process. In case of very technical studies, such as programming, in-depth technical knowledge is also important. Sołtysiak [50] proved that an effective education in electronic learning can develop soft skills among students [49]. At the same time, our statistical results showed that social media plays an important role in acquiring new skills [50]. Our study showed that 123 respondents (112 e-learning platform users and 11 nonusers) stated that the use of the platform does not require any initial technical competence (Table 1).

Students like to use e-learning platforms because they allow materials to be studied electronically: 151 e-learning platform users out of a total of 165 (15.9\% based on the total number of respondents) responded positively to this question, compared with only 14 respondents who were nonusers of e-learning platforms (Table 1); 103 respondents (10.21\%) from the total users of e-learning platforms ( $n=1008)$ believe that e-learning platforms allow for the continuous assessment of knowledge and 134 respondents (13.29\%) believe that using e-learning platforms saves them money by reducing their transport costs (they do not have to go to college every day). Moreover, 124 respondents who were users of e-learning platforms $(12.30 \%)$ said that they like virtual classes for teamwork on different projects. Other advantages offered by e-learning platforms that were mentioned included more efficient technical solutions such as gamification, VR, and AR (mentioned by 114 e-learning platform users $(11.04 \%))$, enabling online conferencing via Skype (mentioned by 83 e-learning platform users $(8.04 \%)$ ), and the fact that the evaluation is objective (mentioned by 72 e-learning platform users $(6.97 \%)$ ). Likewise, 83 e-learning platform users $(8.04 \%)$ mentioned synchronous and asynchronous messaging as a benefit. The study also showed that, while 144 respondents $(13.95 \%)$ felt that e-learning gave them more time to study, 10 respondents $(0.96 \%)$ did not consider this approach an effective solution for learning (Figure 1).

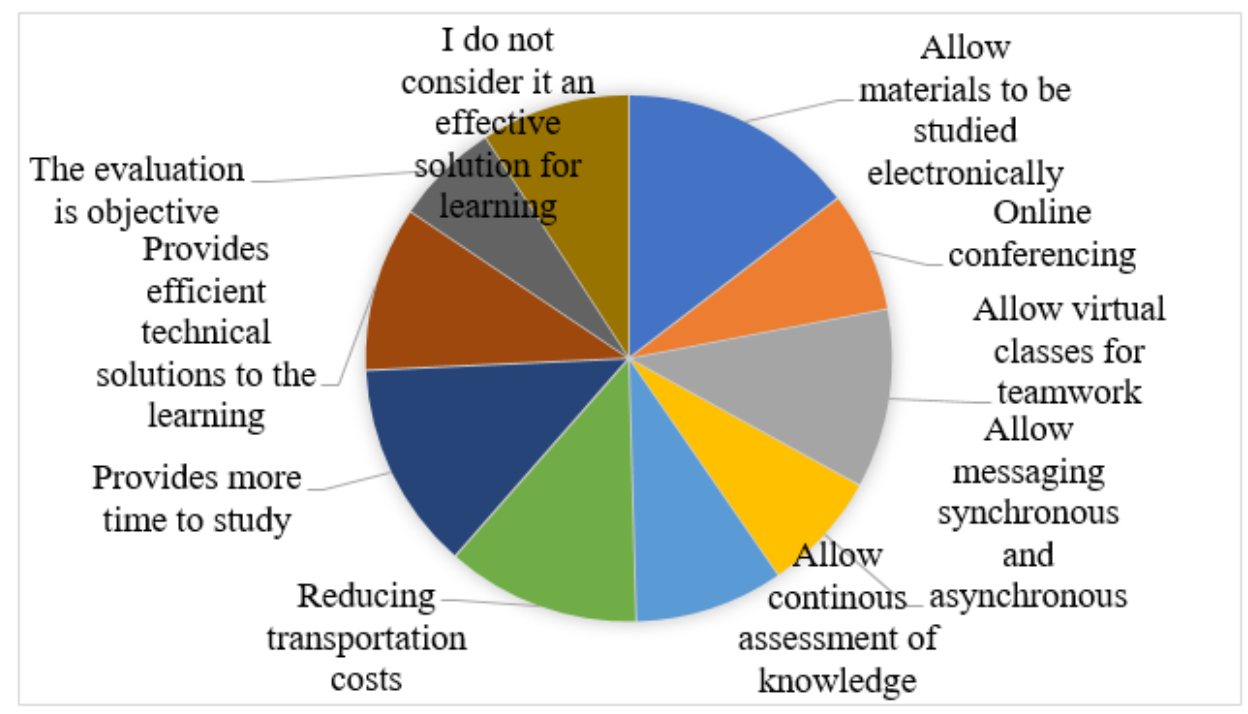

Figure 1. Advantages offered by e-learning platforms.

Compared to these data, other similar studies showed that approximately $80 \%$ of students appreciated the flexibility of e-learning, while only $30 \%$ of students considered that they are better at managing their time using these platforms (Table 1). An important advantage of e-learning shown in other studies is that it reduces learning time compared to the traditional style [51]. Another common opinion was that e-learning simulates or facilitates independent study [52]. Suresh shows respondents' preferences for interactive e-learning methods at $67 \%$ compared to text-driven e-learning or stimulation [53]. For this learning style to be effective, it is also necessary to train the teaching staff appropriately; students, though aware of the benefits of these tools, are limited in their ability to use them [54]. 
At the beginning of the study, it can be observed that most of the students (74\%) who were e-learning platform users $(n=764)$ considered that the balance between learning and social life is assisted by the e-learning process. A small number of e-learning platform users $(8.04 \%, n=83)$ did not agree with this statement, while $17.92 \%(n=185)$ of e-learning platform users were unsure (Figure 2$)$.

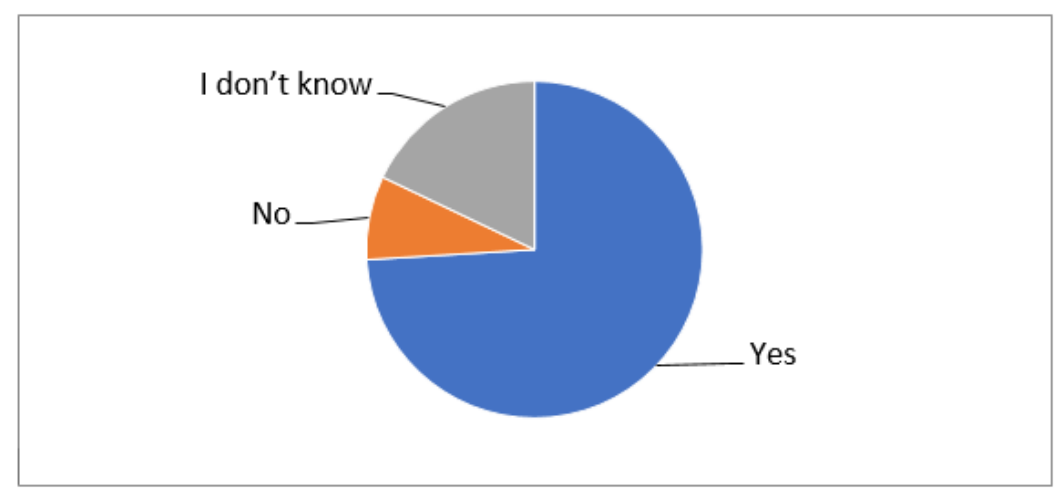

Figure 2. The e-learning system allows a balance between learning and social life.

Of the respondents who were nonusers of e-learning platforms $(n=223), 32.73 \%(n=73)$ did not agree with the statement that e-learning systems allow for a balance to be struck between learning and social life, while $67.26 \%(n=150)$ were unsure.

The results of this study showed that $68.99 \%(n=712)$ of e-learning platform users said that e-learning helps them to increase their level of culture and their living standard, in that they can work during the day and learn in the afternoons or on weekends. Otherwise, they could not afford to pay for their studies; but without higher education, they would be limited to a smaller salary and an inappropriate job. Only $10.94 \%(n=113)$ of e-learning platform users disagreed with this statement, while $20.05 \%(n=207)$ were unsure (Figure 3$)$.

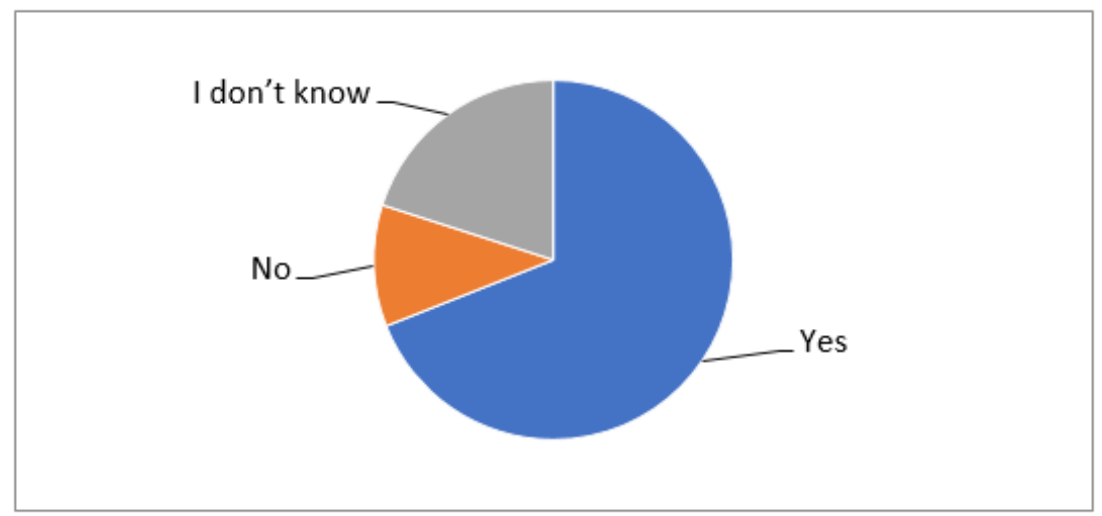

Figure 3. A lack of e-learning platforms would translate into a lower level of culture and living standards (economic).

On the previous question, e-learning platform nonusers $(n=207)$ were asked if a lack of e-learning platforms would translate into a lower level of culture and living standards: $40.35 \%(n=90)$ did not agree, while $52.46 \%(n=117)$ were unsure (Figure 3$)$.

The study followed, in addition to students' perceptions about the use of e-learning platforms, to what extent virtual technologies can influence learning facilities.

\subsection{Respondents' Opinions on VR/AR Technology and E-Learning}

To the semi-closed question about which areas of study VR/AR can be used in, students, mostly from the economics faculties, appreciated the usefulness of these technologies in these areas: technical 
sciences $(n=945)$, social sciences $(n=875)$, arts and architecture $(n=856)$, mathematics and natural sciences $(n=789)$, medicine $(n=765)$, and humanities $(n=150)$. Similar studies showed that students felt virtual technologies were useful in many specialties: economic sciences (management, marketing, economics, finance, accounting, etc.), where VR is used for simulations; social sciences (legal sciences, administrative sciences, communication sciences, psychology, sociology, etc.), where VR/AR allows them to design a subject in simulated reality; and humanities (philology, philosophy, history, cultural studies, theology, literature, etc. $[54,55])$, where VR is used to create a specific environment. However, most of them stated that the fields of study to which VR immersion brings the most advantages are [56]:

- Arts and architecture for developing models/blueprints/plans [57].

- Technical sciences (engineering, construction, etc.) for developing models/blueprints/plans [16].

- Students added that mathematics and medicine can be studied in depth and comprehended better via e-learning platforms. VR/AR can be used in:

- Mathematics and natural sciences (mathematics, informatics, physics, chemistry, chemical engineering, etc.) for testing and simulation [58].

- Medicine (for the study of anatomy, replacing the atlas, for simulating laser operations, etc.).

Some examples of VR/AR applications already tested in medicine are at www.curiscope.com, www.worldofcomenius.com, and www.conquermobile.com, which offer students the opportunity to learn the human skeleton and organs, take apart and re-assemble skeletons, or practise surgical training. In chemistry [59,60], http://educhem-vr.com/ and https://unimersiv.com/review/molecule$\mathrm{vr} /$ let students explore atoms and molecules. In history, www.3ds.com and www.unimersiv.com let students explore reconstructed important historic buildings. An example of using VR/AR in art is 3D painting or interactive experiences at museums (e.g., at Drassanes Museum from Barcelona, holograms bring alive the sailors on a huge Viking ship/galley. In other museums, AR is used for providing additional information. At Woofbert VR's art gallery, visitors can discover pictures interactively or watch an enhanced $360^{\circ}$ version of some shows [55].

Learners can travel all the world with Google Expeditions, visiting national parks in the USA or historic sites in Europe; they can even swim with sharks or dive in the Great Barrier Reef. These expeditions have already been tried by schools in Georgia, USA (Cambridge Elementary and Hilsman Middle). Other participants can get in touch with refugee camps in Syria and Jordan [56].

Students were asked about the advantages and disadvantages of the inclusion of VR/AR in e-learning platforms. Among the advantages mentioned were:

- Adding clarity, visualization, and dynamic interaction for students, because digital technologies with 3D visualization allow for virtual manipulation of artificial objects $(n=970)$

- Increasing attractiveness, motivation, and development of creativity for students $(n=805)$

- Facilitating comprehension of taught content and accelerating the learning process $(n=650)$

- Increasing student satisfaction and motivation; having fun during the learning process $(n=702)$

- The "learning-by-doing" effect—closer to empirical and experimental handling in the real world $(n=444)$

- Including gamification features, which increase curiosity and playfulness, leading to creative solutions $(n=681)$.

AR technology used in education brings about the advantage of covering multiple learning styles; it facilitates observation and exploration, drives performance, achievement, and experimental self-learning, increases motivation and interactivity between students, and in contrast to the traditional educational style, presents the content in a two-dimensional format. AR learning involves many senses: sight, touch, hearing, and smell [20,61,62].

One of the biggest advantages of VR/AR immersion in education is that the competencies obtained in a VR environment are easily transferred to real life. The simulation eliminates the danger of training in a real environment, is independent of time pressures, and can be reproduced as often as 
needed, reducing the expense of testing in real life. It also allows us to survey the past or the future. These assumptions have already been demonstrated by "training of pilots in flight simulators, train drivers in locomotive simulators, training simulations for gas fitters or professional development in the field of emergency medicine" [63,64].

Students think that the most notable disadvantages of VR's inclusion in the e-learning process are cost and technical issues. The equipment used for VR is very expensive and increases the cost of studies. Sometimes technical issues, such as low-resolution content, large file sizes, or a slow or unreliable Internet connection can affect the e-learning process. Other disadvantages associated with e-learning platforms are isolation and the lack of hands-on teaching. Students may feel isolated or miss social interaction (before discovering the forum), and the instructor may not always be available on demand, affecting the teaching flow.

Most students (61\%) use a laptop to access the information provided through the e-learning platform, while others (16\%) prefer a desktop computer. There is a continuous increase in the number of students using modern devices (23\%): mobile phones, tablets, and smart TV. This means that the learning content has to be adapted [63] to the modern devices of the IoT era with responsive sites, proper file sizes, lectures that do not last not too long, special effects, VR, halo features, etc.

In 2014, Cochrane showed that an efficient e-learning system is "Bring Your Own Device" (BYOD), meaning that learning can be experienced via cell phones, which is much appreciated by students for online networking $[65,66]$.

The majority of students consider social media a fun activity for one's spare time $(n=784)$, but they also use it for socialization, solving tasks, and project teamwork $(n=619)$. Some of them $(n=526)$ use social media for gaining knowledge. Most students use Facebook $(n=432)$ and WhatsApp $(n=355)$ in the e-learning process. Other preferred networks are LinkedIn $(n=134)$, Skype $(n=103)$, and ResearchGate $(n=93)$. Some students use specialized networks that provide e-learning courses, such as Discord, Udemy, Edmondo, and Pbworks. Spiru Haret University teachers have published video courses and verification tests on YouTube and Facebook. Students watch and/or listen to the courses and then answer test questions. Our students formed WhatsApp groups and discussed specific problems encountered in the learning process. Some groups invited teachers to offer solutions to their problems. On ResearchGate, Web of Science, and Scopus, students look for newly published research papers and write articles for scientific conferences. Sometimes they look for e-learning courses on Udemy, Edmondo, Pbworks, and LinkedIn. From time to time, teachers set online meetings with students on Skype.

\subsection{Regression Model for Appreciating the Balance between Social Life and Work}

In step two of the analysis, we designed a regression model. The hypothesis of the study (H1) is that a balance between working and social life is influenced by the inclusion of XR facilities in the e-learning process. If students have a high level of culture and living standards, this allows them to invest in technology and easily adopt innovations.

In our model, we included:

- $\quad$ As the dependent variable, the work-life balance (balance variable), presented in Figure 2 and Table 2 as: "The e-learning system allows a balance to be struck between learning and a social life."

- As an independent variable, the inclusion of XR facilities in the e-learning process (XR variable).

- As an independent variable, the level of culture and living standards (culture \& living variable), presented in Figure 3 and Table 2 as "Lack of e-learning platforms would translate into lowering the level of culture and living standards (economic)."

The regression equation is (Table 2): 
Table 2. Logarithmic regression model.

\begin{tabular}{|c|c|c|c|c|}
\hline \multicolumn{5}{|c|}{$\begin{array}{l}\text { Dependent Variable: BALANCE } \\
\text { Method: Least Squares }\end{array}$} \\
\hline \multicolumn{5}{|c|}{ Date: 28/05/20 Time: 18:15 } \\
\hline \multicolumn{5}{|c|}{ Sample: 1032} \\
\hline \multicolumn{5}{|c|}{ Included observations: 1028} \\
\hline Variable & Coefficient & Std. Error & $t$-Statistic & Prob. \\
\hline LOG (CULTURE\&LIVING) & 2.975629 & 1.833290 & 1.623108 & 0.2460 \\
\hline $\mathrm{XR}$ & 1.049003 & 0.105023 & 9.988311 & 0.0099 \\
\hline R-squared & 0.987610 & \multicolumn{2}{|c|}{ Mean dependent variable } & 45.25000 \\
\hline Adjusted R-squared & 0.981415 & \multicolumn{2}{|c|}{ S.D. dependent variable } & 54.41431 \\
\hline S.E. of regression & 7.418065 & \multicolumn{2}{|c|}{ Akaike info criterion } & 7.152566 \\
\hline Sum squared residual & 110.0554 & \multicolumn{2}{|c|}{ Schwarz criterion } & 6.845714 \\
\hline Log likelihood & -12.30513 & \multicolumn{2}{|c|}{ Hannan-Quinn criterion } & 6.479201 \\
\hline Durbin-Watson stat & 2.128881 & & & \\
\hline
\end{tabular}

The $R^{2}$ coefficient of this model is 0.98 , which indicates that $98 \%$ of the balance (dependent variable) variance is determined by the variation of causal variables; only $2 \%$ of this influence cannot be explained by the model. As $R^{2}$ takes values closer to 1 , the regression model better adjusts the data in the sample. In this case, a value of 0.98 demonstrates that the model is good, but other factors might be included in the model (Table 2). Commonly the Chi-Square statistic is used for testing relationships between categorical variables. In our example, we used a similar test, $t$-Statistic, to decide whether to support or reject the null hypothesis.

Furthermore, the adjusted value of $R^{2}(0.98)$ is close to the value of $R^{2}$, which proves that the influence of the independent variables (culture \& living, $X R$ ) is significant to explain the variance of the dependent variable, balance.

Since the adjusted $R^{2}$ value is close to the value of $R^{2}$, this allows for the extension of the proposed regression model to the entire population surveyed. In this case, the variance of the dependent variable decreases with the difference between the two coefficients $(0.9876-0.9814=0.0062)$. This difference can be seen to be below $1 \%$.

The $t$-test for each variable generated validates the model and contributes to the predictive power of regression Prob; the significance threshold of the variables should be less than or around 0.05 . In our case, Prob 0.009 is lower than 0.01 for XR, meaning that the coefficient of this variable is very well estimated and Prob 0.24 is higher than 0.01 for culture \& living standards, meaning that the coefficient of this variable could be estimated better.

The Durbin-Watson test strengthens the model, showing that there is no autocorrelation between the variables.

All the statistics show that we have to accept H1-a work-life balance is easier to achieve if the e-learning process includes XR facilities, and if students' level of culture and living standard is higher, so that they are able to purchase the latest technology and more easily accept innovations.

However, the work-life balance depends not only on the analyzed variables (XR and culture \& living), but also on many other variables that may affect this equilibrium and that are very important nowadays. Students with high digital competency are more likely to adopt XR technology and obtain better grades, and universities that integrate $\mathrm{XR}$ facilities in the learning process are perceived as having better performance.

The way XR technologies are used seems to be more important than the use itself. If the teachers are not comfortable with the technology, they lose credibility with students. Furthermore, if students do not associate XR simulation with deep content study, they will only manage superficial learning.

Due to XR, social networks, and mobile technology spread, a new trend has appeared: the Social Internet of Things. This allows teams to interact in XR with objects in the real world and develop projects together through $360^{\circ}$ video selfies. 
There are apps such as Nearpod VR, EON creator AVR, Audio Response Systems from the Technical University in Graz, and Social Virtual of Facebook that allow realistic, 3D student-teacher interaction in virtual worlds, containing pre-prepared virtual field trips that can be changed by the teacher to fit customized learning scenarios, making available to the student/teacher an AV/AR library or analytical database, and empowering the teacher to deliver feedback to students via an AR app [56,63,65-68].

Furthermore, the classroom of the future will be designed as a thinking lab that integrates modern technologies (interactive detachable workstations, shareable smartboards, and interactive video display walls) and facilities (XR). Student integration into the labor market depends on the field of study, high-performing teachers, and adequate communication between academics and students [69].

\section{Conclusions}

Our research demonstrates that students prefer to use new technologies in education, such as XR, because of the high interactivity, the requirement for motivation and enthusiasm, and the opportunities for experimentation and simulation. Universities have to adopt these technologies and develop new methodologies of training and teaching in accordance with millennial expectations and the technological revolution (modern mobile technologies, interaction with AI, ubiquitous computing and technology, real-time communication with students, and continuous interactions between universities and companies).

Universities have to adopt new and innovative educational curricula, with new methods of teaching. This can be done through improvement of the quality and effectiveness of learning mobility experiences, as well as a new approach to teaching based on the learning-by-doing principle, supported by a stimulating learning environment using $X R$ technologies (VR and AR). Universities can promote interdisciplinary cooperation in the science, technology, engineering, arts, and mathematics (STE(A)M) fields by initiating an Academic Hub in which teachers and students interact, especially through the SIoT (Social Internet of Things). A good example is offered by the University of Graz, Austria [70].

The abovementioned will require a change in the cultural mindset of teachers in countries like Romania, Hungary, and Serbia, to accept the challenges of using new technologies in the teaching process. Business management will be a beneficiary of vocational courses and must accept the option of working and learning from home. In this way, companies and employees will achieve a good work-life balance; higher employee motivation, creativity, and innovation; a higher capacity to adapt quickly to new socioeconomic challenges, through agile management, higher productivity, and higher corporate responsibility, assimilating the principles of the circular economy; and a healthier population that will not need extra funding for the health system.

Modern students must be prepared for the businesses of the future, able to solve different problems with the new skills acquired. This should be possible due to the innovative mindset of the teachers and their ability to cope with disruptions and new technologies. These skills will bring about a competitive advantage and facilitate the smooth transition from school to the business world.

This article offers a new perspective on future educational applications, analyzing the factors that have a positive and negative influence on the quality of the learning environment. With a focus on modern technologies that boost distance and classroom learning, it also prepares students for the interaction between universities and the business field. The graduates of this system will be prepared to embrace the challenges of the circular economy. Moreover, a work-life balance could be more easily reached if XR facilities are included in e-learning and if students' level of culture and living standards is higher, as they will be able to invest in technology and accept innovations more easily, which are marks of a sustainable education.

\section{The Limitations of the Research}

Although we studied a large sample, it was not statistically representative, therefore, our results cannot be generalized to the level of each country participating in the study. This research can 
open up new horizons for panel research that can be repeated at some point. In future research, we will analyze other variables (e.g., government policies to support education) that influence the work-life balance, such as overcoming skill mismatches through the creation of communities that bridge academia and business in different countries, in specific transdisciplinary areas (creating industries: design, audiovisual, ITC, enabling technologies, etc.), to increase HE and B2B capacity to operate at a transnational level, share ideas, and develop the best practices and methods.

Author Contributions: Author Contributions: Conceptualization, R.B.-M.-T,. (Rocsana Bucea-Manea-T,oniş) and V.E.S.; methodology, R.B.-M.-T. (Rocsana Bucea-Manea-Țoniş) and V.E.S.; software, R.B.-M.-T. (Rocsana Bucea-Manea-Toniş); validation, R.B.-M.-T. (Radu Bucea-Manea-T,oniş), D.I., and N.M.; formal analysis, N.M.; investigation, R.B.-M.-T. (Rocsana Bucea-Manea-Toniş), V.E.S. and N.M.; resources, R.B.-M.-T. (Rocsana Bucea-Manea-Toniş), R.B.-M.-T, (Radu Bucea-Manea-Toniş), C.B., N.M. and D.I; data curation, R.B.-M.-T. (Radu Bucea-Manea-Toniş) and C.B; writing—original draft preparation, R.B.-M.-T. (Rocsana Bucea-Manea-Toniş) and V.E.S.; writing-review and editing, R.B.-M.-T. (Rocsana Bucea-Manea-Toniş) and V.E.S.; visualization, N.M.; supervision, R.B.-M.-T. (Rocsana Bucea-Manea-Toniş); project administration, V.E.S. All authors have read and agreed to the published version of the manuscript.

Funding: This research received no external funding.

Conflicts of Interest: The authors declare no conflict of interest.

\section{References}

1. Alonso, R.S.; Prieto, J.; Garcia, Ó.; Corchado, J.M. Collaborative learning via social computing. Front. Inf. Technol. Electron. Eng. 2019, 265-282. [CrossRef]

2. Yu, W.; Chi, S.; Shi, C. Research on Application Mode of VR/AR Technology in Education and Teaching. In Proceedings of the 2018 3rd International Social Sciences and Education Conference, Diyarbakir, Turkey, 14-17 November 2018; Francis Academic Press: London, UK, 2018; pp. 233-236.

3. Ma, C.G.; Kulshrestha, S.; Shi, W.; Okada, Y.; Bose, R. E-learning Material Development Framework Supporting VR/AR Based on Linked Data for IoT Security Education. In Advances in Internet, Data E Web Technologies, Proceedings of the International Conference on Emerging Internetworking, Tirana, Albania, 15-17 March 2018; Barolli, L., Xhafa, F., Javaid, N., Spaho, E., Kolici, V., Eds.; Springer: Berlin, Germany, 2018; pp. 479-491.

4. Shoikova, E.; Nikolov, R.; Kovatcheva, E. Smart Digital Education Enhanced by AR and IoT Data. In Proceedings of the 12th International Technology, Education and Development Conference (INTED), Valencia, Spain, 5-7 March 2018; pp. 5861-5871.

5. Fombona, J.; Pascual-Sevillano, M.A.; Gonzalez-Videgaray, M. M-learning and Augmented Reality: A Review of the Scientific Literature on the WoS Repository. Comunicar 2017, 52, 63-71. [CrossRef]

6. Almenara, J.C.; Robles, B.F. Emerging digital technologies come into the University: AR and VR. RIED 2018, 21, 119-138. [CrossRef]

7. Cipresso, P.; Giglioli, I.A.C.; Raya, M.A.; Riva, G. The Past, Present, and Future of Virtual and Augmented Reality Research: A Network and Cluster Analysis of the Literature. Front. Psychol. 2018, 9, 2086. [CrossRef]

8. El Kabtane, H.; El Adnani, M.; Sadgal, M.; Mourdi, Y. Toward an Occludes Augmented Reality Framework in E-Learning Platforms for Practical Activities. J. Eng. Sci. Technol. 2018, 13, 394-408.

9. Zantal-Wiener, A. The State of Virtual Reality: Were We Are, and What's to Come in 2019. Available online: https://blog.hubspot.com/news-trends/state-of-virtual-reality (accessed on 15 February 2019).

10. Huckle, J.; Sterling, S. Education for Sustainability; Earthscan Publications: London, UK, 1996.

11. Kirschner, P.A.; Kreijns, K.; Phielix, C.; Fransen, J. Awareness of cognitive and social behavior in a CSCL environment. J. Comput. Assist. Learn. 2015, 31, 59-77. [CrossRef]

12. Viltard, L.A.; Viltard, L. Corporate University: An implementation case analysis, in Argentina. Indep. J. Manag. Prod. 2018, 9, 1235-1253. [CrossRef]

13. Novak, E. A critical review of digital storyline-enhanced learning. Educ. Technol. Res. Dev. 2015, 63, 431-453. [CrossRef]

14. Dascalu, M.-I.; Bodea, C.-N.; Moldoveanu, A.; Mohora, A.; Lytras, M.D.; De Pablos, P.O. A recommender agent based on learning styles for better virtual collaborative learning experiences. Comput. Hum. Behav. 2015, 45, 243-253. [CrossRef] 
15. Barzilai, S.; Blau, I. Scaffolding game-based learning: Impact on learning achievements, perceived learning, and game experiences. Comput. Educ. 2014, 70, 65-79. [CrossRef]

16. Schiffeler, N.; Abdelrazeq, A.; Stehling, V.; Isenhardt, I.; Richert, A. How AR-E Your Seminars?! Collaborative Learning with Augmented Reality in Engineering Education. In Proceedings of the 12th International Technology, Education and Development Conference, Valencia, Spain, 5-7 March 2018; pp. 8912-8920.

17. Soo, J.; Crystal, H.; Jihye, O.; Chang, S.J. Application of virtual \& augmented reality for training and development. In Proceedings of the Academy of Human Resource Development International Research Conference, Marriott Richmond, VA, USA, 14-17 February 2018.

18. Iqbal, M.M.; Mumtaz, K.; Khalid, S.; Rafiq, T.; Owais, S.M.; Al Achhab, M. An E-Assessment Framework for Blended Learning with Augmented Reality to Enhance the Student Learning. Eurasia J. Math. Sci. Technol. Educ. 2017, 13, 4419-4436. [CrossRef]

19. Abreu, R.; Almeida, F. E-Learning in Mixed Reality Landscape: Emerging Issues and Key Trends in Scientific Research. In Proceedings of the 12th International Technology, Education and Development Conference (INTED), Valencia, Spain, 5-7 March 2018; pp. 6181-6187.

20. Tulgar, A.T. In Between Reality and Virtuality: Augmented Reality in Teaching English to Young Learners. Selçuk Üniv. Sos. Bilim. Enst. Derg. 2019, 41, 356-364.

21. Gejendhiran, S.; Anicia, S.A.; Vignesh, S.; Kalaimani, M. Disruptive Technologies-A promising key for Sustainable Future Education. Procedia Comput. Sci. 2020, 172, 843-847. [CrossRef]

22. Bacca-Acosta, J.; Baldiris, S.; Fabregat, R.; Graf, S.; Kinshuk, G. Augmented Reality Trends in Education: A Systematic Review of Research and Applications. Educ. Technol. Soc. 2014, 17, 133-149.

23. Akçayır, M.; Akçayır, G. Advantages and challenges associated with augmented reality for education: A systematic review of the literature. Educ. Res. Rev. 2017, 20, 1-11. [CrossRef]

24. Johnson, L.; Adams, S.B.; Cummins, M.; Estrada, V.; Freeman, A.; Hall, C. NMC Horizon Report: 2016 Higher Education Edition. Available online: https://www.learntechlib.org/p/171478/ (accessed on 25 March 2020).

25. Cabero-Almenara, J.; Barroso-Osuna, J. The educational possibilities of Augmented Reality. J. New Approaches Educ. Res. 2016, 5, 44-50.

26. Mahmud, S.N.D.; Husnin, H.; Soh, T.M.T. Teaching Presence in Online Gamified Education for Sustainability Learning. Sustainability 2020, 12, 3801. [CrossRef]

27. Richardson, J.C.; Maeda, Y.; Lv, J.; Caskurlu, S. Social presence in relation to students' satisfaction and learning in the online environment: A meta-analysis. Comput. Hum. Behav. 2017, 71, 402-417. [CrossRef]

28. Cabero-Almenara, J.; Osuna, J.B.; Llorente-Cejudo, C.; Martínez, M.D.M.F. Educational Uses of Augmented Reality (AR): Experiences in Educational Science. Sustainability 2019, 11, 4990. [CrossRef]

29. Erasmus+ call, KA2, Strategic Partnerships in the Field of Education and Training. Available online: https: //ec.europa.eu/programmes/erasmus-plus/opportunities/calls_en (accessed on 15 May 2020).

30. EC. New Skills Agenda for Europe-Digital Skills and Jobs Coalition. 2016. Available online: https: //ec.europa.eu/social/main.jsp?catId=1223\#coalition (accessed on 9 May 2020).

31. EC. New Skills Agenda for Europe-EU Skills Profile Tool for Third Country Nationals. Available online: https://ec.europa.eu/social/main.jsp?catId=1412\&langId=en2017 (accessed on 9 May 2020).

32. EC. New Skills Agenda for Europe-Recommendation on Key Competences for Lifelong Learning 2018. Available online: https://eur-lex.europa.eu/legal-content/EN/TXT/?uri=uriserv:OJ.C_.2018.189.01.0001.01. ENG (accessed on 9 May 2020).

33. Soldi, R.; Cavallini, S.; Friedl, J.; Volpe, M.; Zuccaro, C.P. A New Skills Agenda for Europe. 2016. Available online: https://cor.europa.eu/en/engage/studies/Documents/New-Skills-Agenda-Europe.pdf (accessed on 9 May 2020).

34. Tonis, R.B.M.; Braicu, C. Present and perspectives of the intellectual capital management in Romanian university environment. Indep. J. Manag. Prod. 2019, 10, 1645-1661. [CrossRef]

35. Qinghu, Y. Study on Integration Innovation Development of VR Technology and Education. In Advances in Intelligent Systems Research, Proceedings of the 8th International Conference on Management, Education and Information, Shenyang, China, 21-23 September 2018; Atlantis Press: Paris, France, 2018.

36. Gikas, J.; Grant, M.M. Mobile computing devices in higher education: Student perspectives on learning with cellphones, smartphones \& social media. Internet High. Educ. 2013, 19, 18-26. [CrossRef] 
37. Chen, C.-H.; Liu, C.-L.; Hui, B.P.H.; Chung, M.-L. Does Education Background Affect Digital Equal Opportunity and the Political Participation of Sustainable Digital Citizens? A Taiwan Case. Sustainability 2020, 12, 1359. [CrossRef]

38. Rehder, K.J.; Adair, K.C.; Hadley, A.; McKittrick, K.; Frankel, A.; Leonard, M.; Frankel, T.C.; Sexton, J.B. Associations between a New Disruptive Behaviors Scale and Teamwork, Patient Safety, Work-Life Balance, Burnout, and Depression. Jt. Comm. J. Qual. Patient Saf. 2019, 46, 18-26. [CrossRef] [PubMed]

39. Brauner, C.; Wöhrmann, A.M.; Frank, K.; Michel, A. Health and work-life balance across types of work schedules: A latent class analysis. Appl. Ergon. 2019, 81, 102906. [CrossRef] [PubMed]

40. Adkins, C.L.; Premeaux, S. A cybernetic model of work-life balance through time. Hum. Resour. Manag. Rev. 2019, 29, 100680. [CrossRef]

41. Santander, N.M.; Lidón-Moyano, C.; González-Marrón, A.; Bunch, K.; Sanchez, J.C.M.; Martínez-Sánchez, J.M. Attitudes toward working conditions: Are European Union workers satisfied with their working hours and work-life balance? Gac. Sanit. 2019, 33, 162-168. [CrossRef] [PubMed]

42. Smeltzer, S.C.; Sharts-Hopko, N.C.; Cantrell, M.A.; Heverly, M.A.; Wise, N.J.; Jenkinson, A. Perceptions of academic administrators of the effect of involvement in doctoral programs on faculty members' research and work-life balance. Nurs. Outlook 2017, 65, 753-760. [CrossRef]

43. Zhai, X. Practical application research on teaching reform of logistics management specialty under the guidance of Internet + VR Technology. Logist. Eng. Manag. 2018, 40, 163-165.

44. Gao, W.; Wang, Y.; Wu, Q.; Wang, C. The application and development prospect of educational games based on VR technology in English Teaching. Software 2018, 39, 60-65.

45. Hajli, M.; Lin, X. Exploring the Security of Information Sharing on Social Networking Sites: The Role of Perceived Control of Information. J. Bus. Ethic 2014, 133, 111-123. [CrossRef]

46. Li, N.; Kirkup, G. Gender and cultural differences in Internet use: A study of China and the UK. Comput. Educ. 2007, 48, 301-317. [CrossRef]

47. Schumacher, P.; Morahan-Martin, J. Gender, Internet and computer attitudes and experiences. Comput. Hum. Behav. 2001, 17, 95-110. [CrossRef]

48. Olivero, N.; Lunt, P. Privacy versus willingness to disclose in e-commerce exchanges: The effect of risk awareness on the relative role of trust and control. J. Econ. Psychol. 2004, 25, 243-262. [CrossRef]

49. Chu, R.J.-C. How family support and Internet self-efficacy influence the effects of e-learning among higher aged adults-Analyses of gender and age differences. Comput. Educ. 2010, 55, 255-264. [CrossRef]

50. Sołtysiak, W. Soft Competences as Measurement for E-Learning Effectiveness. In Proceedings of the 5th International Multidisciplinary Scientific Conference on Social Sciences and Arts SGEM 2018, Albena, Bulgaria, 26 August-1 September 2018; pp. 733-738.

51. Thejeswar, E.P.; Thenmozhi, M.S. Educational Research-iPad System vs Textbook System. Res. J. Pharm. Technol. 2015, 8, 1158. [CrossRef]

52. Gudea, N.; Fărăgău-Dragoş, M.; Gudea, A. E-learning platform in Faculty of Veterinary Medicine Cluj-Napoca-The students' perception in 2018. J. Educ. Sci. Psychol. 2019, 9, 65-72.

53. Suresh, M.; Vishnu Priya, V.; Gayathri, R. Effect of e-learning on academic performance of undergraduate students. Drug Invent. Today 2018, 10, 1797-1800.

54. Kantsedal, N.; Ponomarenko, O.; Dorohan'-Pisarenko, L.; Liaska, O. The methods of using interactive technologies during teaching foundations of scientific research at higher educational establishments. Indep. J. Manag. Prod. 2019, 10, 778-797. [CrossRef]

55. Dobrova, V.; Labzina, P.; Ageenko, N.; Nurtdinova, L.; Elizarova, E. Virtual and Augmented Reality in Language Acquisition. In Advances in Social Science Education and Humanities Research, Proceedings of the International Conference on the Theory and Practice of Personality Formation in Modern Society (ICTPPFMS 2018), Yurga, Russia, 20-22 September 2018; Atlantis Press: Paris, France; Volume 198, pp. 218-223.

56. Klampfer, A. Virtual/Augmented Reality in Education. Analysis of the Potential Applications in the Teaching/Learning Process. In ATINER'S Conference Paper Series; ATINER: Athens, Greece, 2016; Volume EDU2017-2214, pp. 1-25.

57. Wang, P.; Wu, P.; Wang, J.; Chi, H.-L.; Wang, X. A Critical Review of the Use of Virtual Reality in Construction Engineering Education and Training. Int. J. Environ. Res. Public Health 2018, 15, 1204. [CrossRef] 
58. Lorenzo, C.; Lorenzo, E. When Learning Happens Through a Cycle of Invention, Design and Digital Fabrication as Students Bring Their Ideas to Life. In Proceedings of the 12th International Technology, Education and Development Conference (INTED 2018), Valencia, Spain, 5-7 March 2018; pp. 7836-7844.

59. Hernandez, R.J.G.; Kranzlmüller, D. NOMAD VR: Multiplatform virtual reality viewer for chemistry simulations. Comput. Phys. Commun. 2019, 237, 230-237. [CrossRef]

60. Su, C.; Cheng, T.-W. A Sustainability Innovation Experiential Learning Model for Virtual Reality Chemistry Laboratory: An Empirical Study with PLS-SEM and IPMA. Sustainability 2019, 11, 1027. [CrossRef]

61. Dalim, C.S.C.; Dey, A.; Piumsomboon, T.; Billinghurst, M.; Sunar, M.S. TeachAR: An Interactive Augmented Reality Tool for Teaching Basic English to Non-Native Children. In Proceedings of the 2016 IEEE International Symposium on Mixed and Augmented Reality (ISMAR-Adjunct), Merida, Mexico, 19-23 September 2016; pp. 82-86. [CrossRef]

62. Fernandez, M. Augmented Virtual Reality: How to İmprove Education Systems. High. Learn. Res. Commun. 2017, 7, 1-15. [CrossRef]

63. Jenewein, K.; Hundt, D. Wahrnehmung und Lernen in virtueller Realität-psychologische Korrelate und exemplarisches Forschungsdesign. In Arbeitsbericht; Otto-von-Guericke-Universität: Magdeburg, Germany, 2009 ; p. 67.

64. Cochrane, T.; Antonczak, L.; Keegan, H.; Narayan, V. Riding the wave of BYOD: Developing a framework for creative pedagogies. Res. Learn. Technol. 2014, 22. [CrossRef]

65. Mehlitz, M.A. Development of a Medical Virtual Reality Laboratory and a VR-Aided Neuropsychological Testing System with a Pre-Clinical and Clinical Evaluation Study 2004. Available online: https://www. deutschedigitalebibliothek.de/binary/TDSPKXN6FO5UIVNVM2HCNFN3OO3UMY3H/full/1.pdf (accessed on 20 April 2019).

66. Dabbagh, N.; Kitsantas, A. Personal Learning Environments, social media, and self-regulated learning: A natural formula for connecting formal and informal learning. Internet High. Educ. 2012, 15, 3-8. [CrossRef]

67. Hagenhofer, T. Social Virtual Learning. 2020. Available online: http://www.social-augmented-learning.de/ (accessed on 15 February 2019).

68. Köhler, T.; Münster, S.; Schlenker, L. Didactics of Virtual Reality, Didactics of Higher Education Characterised by Heterogeneity and Diversity; Books on Demand GmbH: Norderstedt, Germany, 2017; pp. 99-112.

69. Tarabasz, A.; Selaković, M.; Abraham, C. The Classroom of the Future: Disrupting the Concept of Contemporary Business Education. Entrep. Bus. Econ. Rev. 2018, 6, 231-245. [CrossRef]

70. Brudermann, T.; Aschemann, R.; Füllsack, M.; Posch, A. Education for Sustainable Development 4.0: Lessons Learned from the University of Graz, Austria. Sustainability 2019, 11, 2347. [CrossRef] 